\title{
A mulher japonesa vivenciando o câncer cérvico-uterino: um estudo de caso com abordagem da fenomenologia social
}

\author{
A JAPANESE WOMAN GOING THROUGH CERVICAL UTERINE CANCER: \\ A CASE STUDY WITH THE SOCIAL PHENOMENOLOGY APPROACH
}

LA MUJER JAPONESA VIVENCIANDO EL CÁNCER CERVICO-UTERINO: UN ESTUDIO DEL CASO CONABORDAJE FENOMENOLÓGÍA SOCIAL

\section{Rosa Yuka Sato Chubaci ${ }^{1}$, Miriam Aparecida Barbosa Merighi², Yumi Yasumori ${ }^{3}$}

\section{RESUMO}

Trata-se de estudo sobre a experiência de uma mulher japonesa, com câncer cérvicouterino, realizado em um hospital da cidade de Osaka-Japão, no qual se utilizou o "estudo de caso" com abordagem da Fenomenologia Social de Alfred Schütz. Objetivou-se conhecer o significado da doença e da hospitalização para essa mulher, buscando compreender os motivos que envolvem a sua ação. Por meio da análise dos dados, foi possível compreender que o processo da hospitalização deve ser visto respeitando, além da característica individual, o mundo cultural que nos remete às ações humanas e que exerce influência importante no comportamento e atitude em relação à doença e hospitalização.

\section{DESCRITORES}

Pesquisa qualitativa.

Saúde da mulher.

Hospitalização.

\begin{abstract}
This is the study of the experience of a Japanese woman with cervical uterine cancer carried out in a hospital in the city of Osaka, Japan, using Alfred Schütz's "case study" with the Social Phenomenology approach. The aim was to grasp the meaning of the disease and of hospitalization for this woman, and to try to understand the reasoning around her action. Through the analysis of the data, it was possible to understand that the hospitalization process has to be seen respecting, in addition to individual characteristics, the cultural world, which remits us to human actions and is an important influence on the behavior and attitude regarding the disease and hospitalization.
\end{abstract}

\section{KEY WORDS}

Qualitative research.

Women's health.

Hospitalization.

\section{RESUMEN}

Se trata de un estudio sobre la experiencia de una mujer japonesa, con cáncer cérvico-uterino, realizado en un hospital de la ciudad de Osaka-Japón, en el cual se utilizó el "estudio de caso" con abordaje de la Fenomenología Social de Alfred Schütz. El objetivo fue conocer el significado de la enfermedad y de la hospitalización para esa mujer, buscando comprender los motivos que involucran su acción. Por medio del análisis de los datos, fue posible comprender que el proceso de la hospitalización debe ser visto respetando, además de la característica individual, el mundo cultural que nos remite a las acciones humanas y que ejerce influencia importante en el comportamiento y actitud en relación a la enfermedad y hospitalización.

\section{DESCRIPTORES}

Investigación cualitativa. Fenomenologia Social. Hospitalización.
1 Mestre em enfermagem, Doutoranda em Enfermagem na Escola de Enfermagem da Universidade de São Paulo (EEUSP). Bolsista da FAPESP. chubaci@usp.br.

2 Professora Livre-docente do Departamento Maternoinfantil e Psiquiátrica da EEUSP. Lesami@ig.com.br.

3 Professora Titular da Escola de Enfermagem da Universidade da Cidade de Osaka - Japão. 
Rosa Yuka Sato Chubaci Miriam Ap. Barbosa Merighi Yumi Yasumori (a) Grupo étnico como um grupo social com um determinado status, inserido em um grande sistema social, sendo que cada grupo possui, em sua base, traços complexos de religiosidade, língua sexo, estilo de vida, ancestralidade, raça e características físicas ${ }^{(1)}$

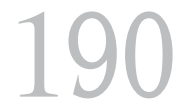

Rev Esc Enferm USP 2005; 39(2):189-94.

\section{INTRODUÇÃO}

A experiência profissional levou-nos a observar que a hospitalização faz com que as pessoas, principalmente os imigrantes provenientes de diferentes grupos étnicos ${ }^{(a)}$, sintam-se limitadas em suas ações, tornando-se, muitas vezes, dependentes para a realização das suas necessidades mínimas. São afastadas de seu ambiente familiar, do seu cotidiano, interrompendo, assim, suas atividades sociais e profissionais.

$\mathrm{O}$ interesse pelo tema da hospitalização do imigrante japonês surgiu durante a trajetória profissional de uma das autoras que faz parte da comunidade japonesa do Brasil, e que ao vivenciar cuidados a pacientes de diferentes origens étnicas, deparou-se com situações diversas em que os imigrantes japoneses enfrentavam, em silêncio, com algumas dificuldades relacionadas aos seus hábitos e costumes ou mesmo com a questão da comunicação verbal. Como parte das suas atividades do curso de pós-graduação, teve oportunidade de permanecer durante três meses na Universidade da cidade de Osaka - Japão, onde coletou dados para a Tese de Doutorado. Naquela ocasião, foi possível realizar algumas entrevistas com mulheres com câncer cérvicouterino em um hospital da região.

Para este texto, destacamos uma entrevista que consideramos repleta de significados e que passamos a apresentá-la sob a forma de estudo de caso.

Tivemos como objetivo conhecer o significado da doença e da hospitalização desta mulher japonesa, buscando compreender os motivos que envolvem a sua ação.

Acreditamos que este estudo poderá contribuir para melhor compreender o paciente imigrante japonês brasileiro, já que uma pesquisa realizada com este grupo étnico mostrou que a sua vivência durante a hospitalização é repleta de influências culturais ${ }^{(2)}$

\section{OREFERENCIAL TEÓRICO-FILOSÓFICO}

Optamos por realizar um estudo, de abordagem qualitativa, do tipo estudo de caso, usando o Referencial Teórico-Metodológico de Alfred Schütz.

$\mathrm{Na}$ fenomenologia a experiência não se faz sobre o fenômeno (experiência do experimentalista), mas mais do que isso, é a experiência do fenômeno e daquilo que funda toda experiência.
Nesse sentido, a doença, tal como é vivida pelas pessoas tem dois aspectos que precisam ser levados em consideração: um é de natureza estrutural e formal que permite entender a doença tal como é, nela mesma, em qualquer lugar do mundo. Outra de natureza material ou de conteúdo que expressará a situação existencial concreta do ser doente, portador de tal doença, que se apresenta através de sua corporeidade, de sua linguagem, de sua vida sócioeconômica e cultural e que difere de um lugar para outro, pois está vinculada à historicidade própria de cada doente.

A fenomenologia social de Schütz visa a compreender o mundo com os outros em seu significado intersubjetivo, tendo como proposta a análise das relações sociais, admitida como relações mútuas que envolvem pessoas. Trata da estrutura de significados na vivência intersubjetiva da relação social do face a face, voltando-se portanto, para entender as ações sociais que têm um significado contextualizado, de configuração de sentido social e não puramente individual ${ }^{(3)}$. Busca compreender a vida social, o conjunto de ações onde as relações mútuas acontecem de maneira consciente, colocando em discussão a relação entre a consciência e a ação. Destaca as características próprias de cada relação, cujas ações ocorrem de maneira consciente, pois são intencionais, tendo um significado para o sujeito.

Os homens agem em função de motivações dirigidas a objetivos, que apontam para o futuro, denominadas de "motivos para", e as razões para as suas ações estão enraizadas em experiências do passado, na personalidade que desenvolveu durante sua vida, chamadas de "motivos porque"(4).

Dessa forma, apropriaremos desse referencial porque o fenômeno estudado busca o vivencial do cotidiano do sujeito que interage no mundo social.

\section{TRAJETÓRIA METODOLÓGICA}

Definimos como sujeito da pesquisa uma mulher japonesa, 46 anos, casada, mãe de dois filhos, hospitalizada com diagnóstico de câncer cérvico-uterino.

Os princípios éticos deste estudo foram baseados na Resolução 196/96 sobre as diretrizes e normas regulamentadoras de pesquisa em seres humanos $^{(5)}$. Tivemos, então, a participação desta paciente, após assinatura do Termo de Consentimento Livre e Esclarecido. 
A entrevista foi gravada e concedida no início do ano de 2002, em um hospital da Cidade de Osaka-Japão, na qual utilizamos a seguinte questão norteadora: Fale-me sobre os seus sentimentos de estar experienciando a doença e a hospitalização.

Para compreender o significado da ação vivenciada pela mulher hospitalizada, segui as indicações de pesquisadores em fenomenologia social, ou seja, por meio de leituras atentivas resgatamos os "motivos para" e os "motivos porque" da ação pesquisada ${ }^{(6-7)}$.

\section{ANÁLISE COMPREENSIVA DO DISCURSO}

Sob a luz dos conceitos de Schütz foi possível apreender o significado subjetivo da ação pesquisada, ou seja, o significado que a mulher que experiencia uma doença e hospitalização atribui à sua própria ação.

A ação é influenciada pela estrutura sedimentada das experiências subjetivas prévias do indivíduo, chamada de bagagem de conhecimentos, adquiridas ao longo de sua vida, por meio de experiências vivenciadas ${ }^{(4)}$. A seguir apresentamos trechos das entrevistas que mostram os motivos da ação da mulher em estudo.

Fazia exames todo ano no dia do meu aniversário, assim eu não esquecia de fazê-lo...Fiz isso durante cinco anos, como nunca veio com problemas achei que não precisava ir ao ginecologista. Que bom que esse exame é fácil de fazer, pensava. Mas no ano passado, no verão, comecei a não me sentir bem... procurei o ginecologista sem pensar em algo ruim... perguntou se eu fazia o exame preventivo todo ano, falei que sim...fez o exame ginecológico e quando visualizou o colo do útero, sua voz mudou. Olhei para ele e sua face estava séria, dura...ficamos sabendo que eu estava com câncer de colo de útero.

A ação é vinculada ao significado da experiência vivida. A paciente sempre cuidou de sua saúde, fazia exames periódicos freqüentemente e acabou decepcionando-se, profundamente, quando diagnosticaram a doença.

Fiquei com raiva, muita raiva, eu sempre me preocupei com minha saúde, fiz aquele exame ginecológico todo ano. Para que, então, eu fiz aquele exame, pensei...Fiquei muito frustrada....Então ele me disse que agora que eu tinha a doença tinha que me preocupar em fazer o tratamento... para que fiz o exame, para que servia então todo o cuidado que tive com a minha saúde. Deve ser por isso que tive desconfiança durante o meu tratamento. Fiquei pensando nisso o tempo todo...fiquei internada por cinco meses e meio.

Ao saber da doença, sentiu-se traída, pois sempre cuidou de sua saúde. Tinha a confiança na prevenção que fazia para a detecção precoce do câncer cérvico-uterino. Pode-se entender que existe um motivo porque ela teve uma reação negativa ao tratamento. Uma pessoa que sempre cuidou de sua saúde estava agora vivenciando a facticidade de uma doença e hospitalização.

As ações estão enraizadas em experiências passadas, na personalidade que um homem desenvolveu durante sua vida, denominadas de "motivos porque"(3).

Mesmo com a revolta por estar doente, ela submete-se ao tratamento e volta para casa. Agora, a recidiva da doença passa a fazer parte do seu mundo vida, tendo que enfrentar o tratamento novamente. Relata que viver a doença pela segunda vez está sendo mais difícil.

\begin{abstract}
...quando me disseram que tive a reincidência da doença, fiquei muito, mas muito chocada. Nunca pensei nessa possibilidade... Acho que eu não via essa doença seriamente, pensei que tivesse sarado. Levou muito tempo para eu aceitar esse fato, nem sei se eu aceito até hoje. (chora). Pensei comigo será que agora vou morrer?...Na primeira vez pensei que eu iria sarar com aquele tratamento, acreditava que eu iria sarar... comecei a não ver aquela luz no fundo do túnel e só conseguia ver a escuridão. Será que não vai dar mais? Como será daqui para frente? Acho que a visão para a morte foi mais forte. Quantos anos poderei viver mais? Só pensava nessas coisas.
\end{abstract}

Esta situação pode ser melhor entendida quando percebemos que esta paciente está revivendo o mundo da hospitalização, agindo e reagindo de maneira própria, de acordo com a experiência que já vivenciou na primeira internação. São as vivências armazenadas que estão determinando os elementos relevantes da sua ação. A recidiva da doença faz com que sofra pela possibilidade de caminhar para a morte. Essa realidade do senso comum, o mundo da vida diária é denominada como situação biográfica, ou seja, o modo pelo qual eu ocupo o espaço da ação, interpreto suas possibilidades e me envolvo com seus desafios, e a sedimentação desta experiência passa a ser a condição para a interpretação subseqüente de todos os novos eventos e ações ${ }^{(4)}$.
A mulher japonesa vivenciando o câncer cérvico-uterino: um estudo de caso com a abordagem da fenomenologia social 
Rosa Yuka Sato Chubaci Miriam Ap. Barbosa Merighi Yumi Yasumori
O mundo cotidiano da hospitalização é vivenciado pela paciente não só no enfrentamento da doença, como no relacionamento com as pessoas que, agora, fazem parte da experiência que está vivenciando.

Até gostaria que as enfermeiras e médicos
entendessem o sentimento de uma paciente.
Outro dia eu estava assistindo a um programa
dos Estados Unidos em que mostravam que
as enfermeiras e os médicos não entendem o
sentimento vivido pelo doente, e só as própri-
as pacientes entendem melhor o que uma ou
outra colega está sentindo. É diferente quan-
do uma enfermeira vem e fala para mim que
eu preciso me esforçar e quando uma colega
que é paciente também vem e fala a mesma
coisa. Eu aceito melhor quando a minha cole-
ga vem e fala comigo...

O mundo do senso comum, mundo da vida diária, mundo cotidiano são diversas expressões que indicam o mundo intersubjetivo experimentado pelo homem, sendo esse mundo a essência da ação social, no qual os homens entram em mutual relação e tratam de se entender uns com os outros, assim como consigo mesmo ${ }^{(4)}$.

Ao enfrentar uma nova internação, esta paciente passa a sofrer com a gravidade de sua doença. Tem um relacionamento puramente técnico com a equipe de saúde e principalmente com a enfermagem, evitando o envolvimento emocional com ela.

\begin{abstract}
Será que as pacientes querem que as enfermeiras e médicos cheguem mais perto deles? Eu acho que os pacientes não esperam esse tipo de ajuda. Eu me ajudo junto com outras pacientes, eu não penso em ter um suporte emocional por parte das enfermeiras. Tem uma barreira entre a paciente e a enfermeira que não dá para ser ultrapassado. Eu também só falo até um limite, não gostaria que houvesse comentário sobre a minha pessoa durante a passagem de plantão. Eu não gostaria que falassem sobre a minha pessoa, sobre meus problemas pessoais, meus sentimentos na passagem de plantão, pois seria feita de uma forma tão fria, sem considerar meus verdadeiros sentimentos.
\end{abstract}

A experiência adquirida ao longo de sua vida, chamada por Schütz como bagagem de conhecimentos disponíveis, faz com que se preserve diante da equipe de saúde, pois acredita que ela não entenderia o seu sentimento em relação à doença e à hospitalização.

Esta atitude preservada faz com que ela tenha medo de não ser respeitada como paciente, evitando, assim, a invasão da sua privacidade. A auto-estima, já debilitada pela doença, tenta se proteger de alguma forma.

Tenho desconfiança do que elas podem falar sobre a minha pessoa. Por isso falo só o necessário. Tem algumas enfermeiras que eu até gostaria de falar sobre os meus problemas, mas acabo não falando porque ela pode levar tudo que converso para outras enfermeiras e médicos. Não sei até onde posso conversar. Sabe, as enfermeiras conversam com a gente profissionalmente, pegam tudo como um dado para o relatório, sem nenhum sentimento...

No caso dessa paciente, as palavras comedidas servem como um escudo de proteção, dificultando a aproximação do profissional de saúde. $\mathrm{O}$ fato de não ser considerada como pessoa faz com que crie um limite para as informações aos profissionais de saúde, suscitando, assim, o sentimento de desconfiança. Tem a sua própria atitude natural que é a maneira que o homem experimenta o mundo intersubjetivo, seja o mundo do senso comum, o mundo da vida cotidiana ${ }^{(4)}$.

O relacionamento com a equipe de enfermagem é prejudicado pelo excesso de atividades da Unidade de Internação. Percebe que as enfermeiras são muito ocupadas, não tendo tempo para ela.

Quando quero pedir algo para as enfermeiras, acabo não pedindo porque percebo que estão ocupadas. Todo tempo fico fazendo cerimônia. Tem dia que elas estão ocupadas por ser o dia da cirurgia da Unidade, então procuro não pedir nada. Outro dia olho no rosto da enfermeira que está cuidando de mim e vejo que seu rosto está tenso, então acabo não solicitando também.

Por outro lado, percebe-se que a paciente sente necessidade de ter a atenção voltada para ela, mas acaba suportando a situação, pois considera que poderá atrapalhar o serviço das enfermeiras.

A dificuldade em enfrentar a doença e o tratamento é amenizada ao contar com o apoio das colegas internadas e que estão vivenciando situações semelhantes às dela.

Tem momentos dolorosos em que dá vontade de desistir de lutar, mas quando melhoro, penso em esforçar para melhorar. Cada dia ou é o céu ou o inferno. Converso com as colegas que estão internadas, elas me incentivam, me consolam. Todos estão aqui também para se tratarem, aí sinto que preciso me esforçar. 
Não poderia suportar esta situação se não tivesse a amizade entre as pacientes...Quando vivemos a mesma situação, fica mais fácil entender o sentimento vivido entre nós durante a hospitalização. Falamos umas para outras "vamos nos esforçar, vamos nos esforçar!". Se não temos a mesma dor fica difícil entender, peço desculpas, mas é isso.

Apoiam-se umas nas outras, superando as fases dolorosas do tratamento. Compartilham a ansiedade, a tristeza, a decepção, a angústia, a solidão, numa tentativa de superar os desafios enfrentados no seu dia-a-dia. Acabam vivenciando a ajuda na relação face-a-face, pois para ela a colega que vivencia, também, um câncer está dentro do alcance da sua experiência direta, compartilhando com ela o mesmo espaço e o mesmo tempo.

Essa atitude é melhor entendida quando se percebe que a pessoa divide com o outro um tempo comum, quando sua experiência flui lado a lado com a do outro, quando é possível a qualquer momento, buscar e captar seus pensamentos conforme eles existam. A situação face-a-face pressupõe, então, uma simultaneidade real de cada uma das correntes de consciências distintas, de forma a tornar-se consciente de tal situação, o participante precisa tornar-se consciente de outra pessoa ${ }^{(3)}$.

Diante da experiência que está vivenciando, todo o esforço, a ação social em enfrentar a doença e o tratamento é motivada por um projeto que é direcionado para o futuro.

Quando soube que tive a recidiva, comecei a não ver aquela luz no fundo do túnel e só conseguia ver a escuridão. Será que não vai dar mais?...Pensava mais na minha filha, ela ainda precisa de mim. O meu filho já sabe seguir em frente, mas a minha filha... Tenho tantas coisas para ensinar ainda. Queria ver tantas coisas com ela, por mais que passe a idade eu teria tanta coisa para the ensinar...Sempre penso que para o bem da minha filha eu preciso de mais tempo. Pela minha filha, mais que para mim mesmo, eu preciso viver mais.

Nos momentos mais difíceis é motivada para não desistir: a vontade de estar ao lado da filha. $\mathrm{O}$ sentimento de que ela ainda necessita da sua ajuda constitui-se em um motivo para continuar vivendo. O "motivo para" é um contexto de significado que é construído ou se constrói sobre o contexto de experiências disponíveis no momento da projeção da ação, sendo esta categoria essencialmente subjetiva. Portanto, esta ação só pode ser interpretada pela subjetividade do sujeito, pois somente a própria pessoa pode definir o seu projeto de ação, seu desempenho social ${ }^{(3)}$.
A paciente falou sobre a sua experiência de estar doente e internada pela primeira vez ao conceder esta entrevista. A vontade de ser ouvida fez com que expressasse os seus sentimentos, mostrando "os motivos para" e "porque" levaram-na a agir diante da experiência de estar vivenciando a doença e a hospitalização.

\section{CONSIDERAÇÕES FINAIS}

Por meio deste estudo foi possível compreender que as necessidades da paciente são consolidadas pelo seu entendimento de mundo. A paciente mostrou que o fato de falar e ser ouvida é importante para ser compreendida enquanto mulher vivenciando a doença e a hospitalização.

Mostrou, também, que a mulher japonesa tem a sua fala permeada pela influência cultural, possuindo algumas características comportamentais próprias, assim como foram identificadas no estudo sobre imigrantes japoneses hospitalizados ${ }^{(2)}$ no Brasil. Foi possível perceber que o seu depoimento foi marcado pela presença de alguns conceitos culturais ${ }^{(8)}$, como a auto-restrição, auto-controle em suportar situações angustiantes e/ou aflitivas, e o conformar-se com a situação vivida. A autorestrição pode ser percebida, quando a paciente tem necessidade de algum esclarecimento ou cuidado durante o tratamento e acaba não solicitando à equipe de enfermagem pelo receio de incomodála. Acaba, então, conformando-se com a situação vivida. Dessa forma, a paciente passa a suportar o seu sofrimento e ansiedade. Essas ações típicas da cultura japonesa fazem com que a paciente tenha dificuldade de exteriorizar os seus sentimentos. O mundo da vida cotidiana é um mundo cultural, um mundo de significações, uma textura de sentido que devemos compreender para nos guiar nele; a cultura nos remete às ações humanas, isto é, nas atividades significativas dos sujeitos humanos ${ }^{(4)}$.

Ao retomar nossas inquietações quanto ao cuidado prestado ao imigrante japonês, este estudo de caso com a mulher japonesa hospitalizada permitiu-nos compreender, mais uma vez, que o cuidado deve estar voltado, não somente para a doença e o cuidado técnico, mas também para a pessoa doente, respeitando a sua individualidade, seu contexto social e a sua história.

A compreensão da experiência da hospitalização vivenciada pela paciente japonesa ajudounos a entender um pouco mais o imigrante japonês hospitalizado no Brasil, já que as influências culturais refletem no seu modo de ser dentro do hospital. O processo saúde-doença pode ser melhor en-
A mulher japonesa vivenciando o câncer cérvico-uterino: um estudo de caso com a abordagem da fenomenologia social 
Rosa Yuka Sato Chubaci Miriam Ap. Barbosa Merighi Yumi Yasumori tendido quando o consideramos como parte da experiência cultural do indivíduo.

Foi possível identificar que a paciente japonesa tem dificuldades semelhantes as dos imigrantes japoneses como no relacionamento com a equipe de saúde. Desta forma, a apreensão da experiência da mulher japonesa permitirá melhor compreensão da vivência do nosso imigrante japonês hospitalizado, possibilitando, assim, prestar-lhe uma assistência mais adequada e com qualidade.

A Fenomenologia Social de Alfred Schütz permitiu aprofundar reflexões sobre o agir profissional da equipe de enfermagem que cuida de pacientes de diferentes etnias, por meio da compreensão da ação que a mulher japonesa vivencia com a doença e a hospitalização.

\section{REFERÊNCIAS}

(1) Spector R. Culture, ethnicity and nursing. In: Potter $\mathrm{P}$, Perry A, editors. Fundamental of nursing: concepts, process and practice. Saint Louis: Mosby; 1993. p. 95-116.

(2) Chubaci RYS. A experiência da hospitalização do imigrante japonês. [dissertação] São Paulo (SP): Escola de Enfermagem da USP; 1999.

(3) Schütz A. Fenomenologia del mundo social. Buenos Aires: Paidos; 1972.

(4) Schütz A. El problema de la realidade social. Buenos Aires: Amorrortu; 1974.

(5) Conselho Nacional de Saúde. Resolução n. 196, de 10 de outubro de 1996. Diretrizes e normas regulamentadoras de pesquisa em seres humanos. Brasília (DF): Ministério da Saúde; 1996.
(6) Parga Nina L. Estudo das informações não estruturadas do ENDEF e de sua integração com os dados quantificados. Rio de Janeiro: IBGE; 1976.

(7) Merighi MAB. Enfermeiras obstétricas egressas da Escola de Enfermagem da Universidade de

São Paulo: caracterização e trajetória profissional [tese]. São Paulo (SP): Escola de Enfermagem da USP; 2000.

(8) Shiba G, Oka R. Japanese americans. In: Lipson JG, Dibble SL, Minarik PA, editors. Culture \&nursing care: a pocket guide. California: Regents; 1996. p. $180-90$. 